\title{
RELEVANT PREVALENCE OF Mycoplasma hominis AND Ureaplasma urealyticum SEROGROUPS IN HIV-1 INFECTED MEN WITHOUT URETHRITIS SYMPTOMS
}

\author{
Caio Mauricio Mendes CORDOVA(1) \& Regina A. F. CUNHA(1)
}

\begin{abstract}
SUMMARY
M. hominis and $U$. urealyticum are the better-known mycoplasma species pathogenic to the human genitourinary tract, causing mainly urethritis, bacterial vaginosis and pregnancy complications. In HIV-infected patients, the prevalence and role of these species is still not well known. The aim of this work was to determinate the prevalence of these species in this group of male patients (HIV group), in comparison to a group of men with clinical symptoms of urethritis (STD group). M. hominis was isolated from 7.5\% patients (8/106) and U. urealyticum from $18.9 \%$ patients (20/106) from the HIV group, being among these $62.5 \%$ and $85 \%$ in significant concentrations, respectively. In the STD group these rates were $0.9 \%$ (1/110) for M. hominis and 13.6\% (15/110) for $U$. urealyticum, being $100 \%$ and $93.3 \%$ in significant concentrations, respectively. We could demonstrate infection rates by these mycoplasma species in the HIV group as high as the one found in the STD one, what may indicate the occurrence of opportunistic infections in our population. This fact is discussed here because in immunosuppressed patients, specially M. hominis has been reported causing severe infections, even systemically.
\end{abstract}

KEYWORDS: Mycoplasma; M. hominis; U. urealyticum; HIV; Sexually transmitted diseases; Urethritis; PCR.

\section{INTRODUCTION}

M. hominis and $U$. urealyticum are the better-known mycoplasma species pathogenic to the human genitourinary tract. U. urealyticum is one of the major causes of nongonococcal urethritis in men, being isolated from about $12 \%$ of these cases ${ }^{7}$. It has also been reported causing epididimitis, infectious kidney stones, sexually transmitted reactive arthritis (Reiter's Syndrome) and arthritis in hypogammaglobulinemic patients ${ }^{18}$. In women, its role in the etiology of pregnancy complications is suggestive, inducing pre-term labor, spontaneous abort, infertility, puerperal fever and Pelvic Inflammatory Disease ${ }^{17}$. Transmission of $U$. urealyticum to the fetus or newborn may cause severe broncopulmonar displasias, and even central nervous system (CNS) infections ${ }^{1,6}$. However, a difference of pathogenicity among it's 14 serotypes has been reported, by frequency of isolation from different clinical manifestations, as well as different in vitro properties ${ }^{4}$.

M. hominis may also cause urethritis in men, but in a lesser extension: about $3-4 \%$ of the cases ${ }^{11}$. It is known as the most important agent of bacterial vaginosis, being involved in Pelvic Inflammatory Disease, preterm labor, puerperal fever, and respiratory tract diseases in neonates, infecting the CNS in some cases ${ }^{17}$.

In HIV-infected patients, the prevalence and role of these species is still not well known. However, there have been several reports about $M$. hominis systemic infections in immunosuppressed patients, sometimes severe $^{10}$, as well as for $U$. urealyticum $^{5}$. Therefore, we decided to investigate the prevalence of this species among HIV-1 infected patients without symptoms of urethritis, compared to HIV-1 negative individuals presenting these symptoms.

\section{MATERIALS AND METHODS}

Patients and samples: HIV Group: urethral swabs and urine samples were obtained from 106 adult male patients infected by HIV-1, without clinical symptoms of urethritis. In this group, CD4+ T cells could be obtained from $58(54.7 \%)$ patients. Six patients had CD4+ T cells lower than $50 / \mathrm{mm}^{3}(10.3 \%), 26$ between 50 and $250(44.8 \%), 17$ between 250 and $500(29.3 \%)$, and 9 above 500 (15.5\%). Patients with CD4+ T cells count lower than or equal to $250 / \mathrm{mm}^{3}$ were receiving prophylactic preventive therapy.

STD Group: urethral swabs and urine samples were obtained from 110 adult HIV-negative men attending a STD clinic, with symptoms of urethritis. Patients under antibiotic therapy were excluded from this study. In this group, $47(42.8 \%)$ were infected with Chlamydia trachomatis, 7 $(6.4 \%)$ with Neisseria gonorrhoeae, and 5 (4.5\%) with other microorganisms, including Staphylococcus aureus, Escherichia coli, Enterococcus faecalis, Streptococcus spp., and Trichomonas spp.

(1) Faculdade de Ciências Farmacêuticas da Universidade de São Paulo, SP, Brazil, Phone: (+55) 0113818 3638, fax: (+55) 0118132197.

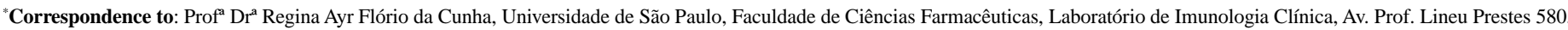
Bloco 17, 05508-900 São Paulo, SP, Brazil, e-mail: reca@usp.br 
Urine samples were concentrated ten fold by centrifugation and, as urethral swab samples, were maintained in $3 \mathrm{ml}$ of $\mathrm{A}_{3 \mathrm{XB}}$ modified transport medium at $4{ }^{\circ} \mathrm{C}$ for 2 hours at most until inoculation in culture media ${ }^{15}$.

Mycoplasma culture: from each sample in transport medium, 0.1 $\mathrm{ml}$ was inoculated in $\mathrm{A} 7$ solid media, and $0.5 \mathrm{ml}$ in tubes containing 2 $\mathrm{ml}$ of Arginine broth, $2 \mathrm{ml}$ of U10 broth, or $2 \mathrm{~mL}$ of SP-4 broth ${ }^{16}$. From each of these tubes, serial ten fold dilutions were made three times in fresh media, resulting in culture of samples in final dilutions of 1:5, 1:50 and 1:500. Cultures were incubated at $37^{\circ} \mathrm{C}$ in $2-3 \% \mathrm{CO}_{2}$ for two weeks, with the exception of SP-4 cultures which were incubated under aerobic conditions, for at least one month, with blind passages every week to new tubes, and also replicated to plates with solid SP-4 medium. Cultures with suspected $M$. fermentans growth were also incubated in Glucose broth under anaerobic conditions, using the GasPack® System and AnaeroGen ${ }^{\mathrm{TM}}$ gas generator (Oxoid Ltd., Basingstoke, Hamshire, England).

Quantification of isolates: quantification of $M$. hominis and $U$. urealyticum present in urethral swab samples was performed by the microtitration technique, once this methodology is well standardized for this kind of material ${ }^{16}$. Briefly, in a 96-well sterile plate, $30 \mu 1$ of sample in transport medium were incubated in $270 \mu \mathrm{l}$ of broth media, namely $\mathrm{U} 10$ for $U$. urealyticum or Arginine for M. hominis, and serial ten fold dilutions from $10^{-1}$ were performed. The higher dilution which changed the color of the indicator present in the broth represents the number of microorganisms in the sample, in CCU (Color Changing Units) for $\mathrm{mL}$.

Mycoplasma identification: Sample preparation for PCR: samples were treated according to the procedure described by BARBEYRAC et $a l .{ }^{2}$. Briefly, $1 \mathrm{ml}$ of mycoplasma culture medium was centrifuged for 15 minutes at $13,000 \times \mathrm{g}$, ressuspended in $0.5 \mathrm{ml}$ of lysis buffer $(1 \mathrm{mM}$ EDTA, $10 \mathrm{mM}$ Tris-HCl, 0.1\% Triton X-100, $200 \mu \mathrm{g} / \mathrm{mL}$ Proteinase K, $\mathrm{pH}=8.0$ ), incubated at $56^{\circ} \mathrm{C}$ for 60 minutes, and at $100{ }^{\circ} \mathrm{C}$ for 10 minutes. Samples were extracted with phenol and phenol/chloroform/ isoamylic alcohol. DNA was precipitated with ethanol and dissolved in $100 \mu \mathrm{l}$ of T.E. buffer (1 mM EDTA, $10 \mathrm{mM}$ Tris-HCl, $\mathrm{pH}=8.0$ ).

M. hominis: identification of M. hominis was performed in samples which changed the color of the indicator in Arginine broth and showed typical Mycoplasma spp. colonies in A7 solid medium. Identification was done by the Ouchterlony's immunodifusion technique ${ }^{12}$ with polyclonal anti- $M$. hominis rabbit serum (kindly produced by Dr. Célia Otsuka Takiy, PROBAC, São Paulo, Brazil), and by the PCR technique ${ }^{8}$, for which two $\mu 1$ of Arginine broth treated as described above were added to the reaction mix. PCR was done in a final volume of $50 \mu \mathrm{l}$, with $1 \mathrm{x}$ Taq Reaction Buffer (Pharmacia Biotech, Uppsala, Sweden), $25 \mathrm{mM}$ dNTP solution (Gibco BRL, Gaithersburg, MD, U.S.A.), $1 \mu$ l of each primer at $30 \mu \mathrm{M}(\mathrm{HOM}+$ : 5'-tgc.acc.atc.tgt.cac.tct.gtt.aac.ctc-3' and UNI: 5'-act.cct.acg.gga.ggc.agc.cgt.a-3'), and $1 \mathrm{U}$ of Taq DNA Polymerase (Pharmacia Biotech, Uppsala, Sweden). Amplification included and initial denaturation step at $95^{\circ} \mathrm{C}$ for 15 minutes, followed by 30 cycles with denaturation at $95{ }^{\circ} \mathrm{C}$ for 30 seconds, primers annealing at $58{ }^{\circ} \mathrm{C}$ for 1 minute and 30 seconds, extension at $72{ }^{\circ} \mathrm{C}$ for 1 minute and 30 seconds, and a final extension step at $72^{\circ} \mathrm{C}$ for 10 minutes. PCR products were detected by agarose gel electrophoresis at $0.8 \%$ with ethidium bromide staining under U.V. light. As a positive control we used DNA from the strain ATCC 23114 of M. hominis. The specificity of M. hominis DNA amplification was evaluated by analysis of the PCR products restriction patterns with the enzyme Kpn I, which yielded one fragment of $299 \mathrm{bp}$ and another of $290 \mathrm{bp}$.

U. urealyticum: samples that showed characteristic Ureaplasma genus colonies in A7 solid medium and changed the color of the indicator in U10 broth were tested using a specific PCR assay for U. urealyticum. The procedure was the same described above for M. hominis, with utilization of different primers (Uu3: 5'-gat.ggt.aag.tta.gtt.gct.gac-3' and Uu4: 5'-acg.acg.tcc.ata.agc.aac.t-3'). Another set of primers (Uu1: 5'cac.aga.tgt.cct.tga.tgt.ac-3' and Uu2: 5'-cac.aga.tgt.cct.tga.tgt.ac-3'), specific for $U$. urealyticum strains of biotype 2, was also used ${ }^{3}$. As positive control of $U$. urealyticum biotype 1 and 2, we used DNA from the strain ATCC 27618 of $U$. urealyticum and from a strain isolated in our laboratory, respectively.

Statistical analysis: data obtained were analysed by the Fisher's exact Test, using the GraphPad InStat ${ }^{\mathrm{TM}}$ software (San Diego, CA, USA).

\section{RESULTS}

\section{M. hominis and $U$. urealyticum isolation and identification from clinical samples}

In the group of HIV-infected patients, 21/106 (19.8\%) had a positive culture for mollicutes, in urethral swabs as well as in urine samples (Table 1). From these, U. urealyticum was isolated in 20 (18.9\%), and M. hominis in $8(7.5 \%)$. In the STD group, M. hominis isolation rate was lower $(0.9 \%$ [1/110]; $p=0.02)$, but there were no significant difference with $U$. urealyticum $(13.6 \%$ [15/110]; $p=0.37)$. All of the strains isolated with presumptive identification of $M$. hominis were confirmed by the

Table 1

Mycoplasma culture and identification in the HIV and STD groups of patients

\begin{tabular}{lcccr}
\hline & \multicolumn{2}{c}{ HIV group } & \multicolumn{2}{c}{ STD group } \\
\cline { 2 - 5 } & Isolation & Relevant concentrations ${ }^{1}$ & Isolation & Relevant concentrations \\
\hline M. hominis & $8 / 106(7.5 \%)^{*}$ & $5 / 8(62.5 \%)$ & $1 / 110(0.9 \%)$ & $1 / 1(100 \%)$ \\
U. urealyticum & $20 / 106(18.9 \%)$ & $17 / 20(85 \%)$ & $15 / 110(13.6 \%)$ & $14 / 15(93.3 \%)$ \\
\hline
\end{tabular}

${ }^{1}$ Relevant concentrations were considered $\geq 10^{4} \mathrm{CCU} / \mathrm{mL}$ for $U$. urealyticum and $\geq 10^{3} \mathrm{CCU} / \mathrm{mL}$ for $M$. hominis.

The statistical difference between the results obtained with the two groups of patients is indicated: ${ }^{*} \mathrm{p} \leq 0.05$. 


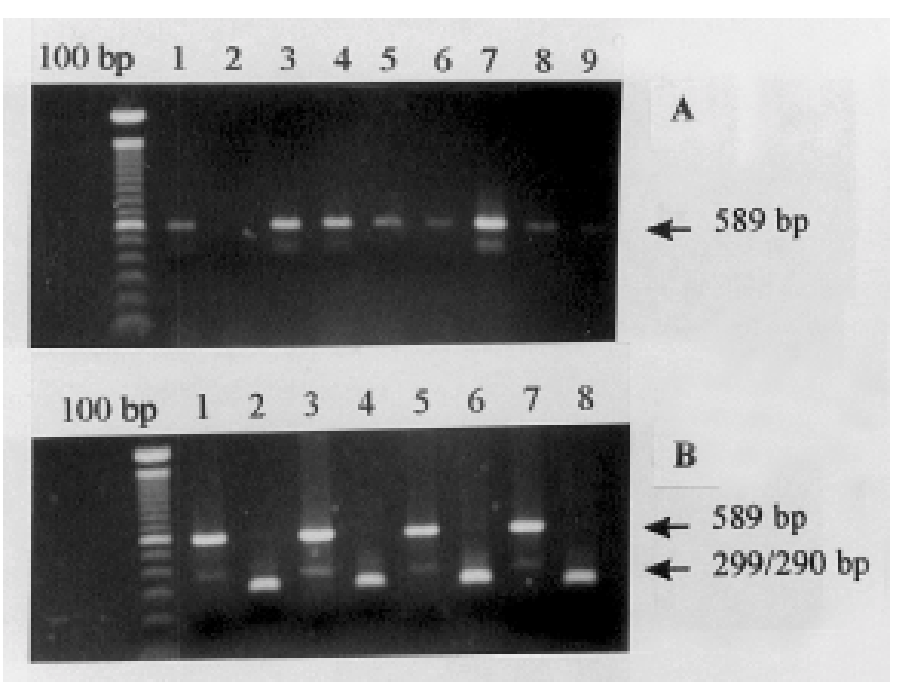

Fig. 1 - A: Identification of suggestive $M$. hominis isolates by PCR with primers $\mathrm{HOM}+$ and UNI-. Lanes 1: Positive control; 2: negative control; 3-8: samples which changed the color of Aginine broth culture tubes. B: Restriction pattern of the amplified products by digestion with the enzyme Kpn I. Lanes 1: Positive control not digested; 3, 5 and 7: samples not digested; 2: digested positive control; 4, 6 and 8: digested samples. Weight marker: $100 \mathrm{bp}$ DNA Ladder.
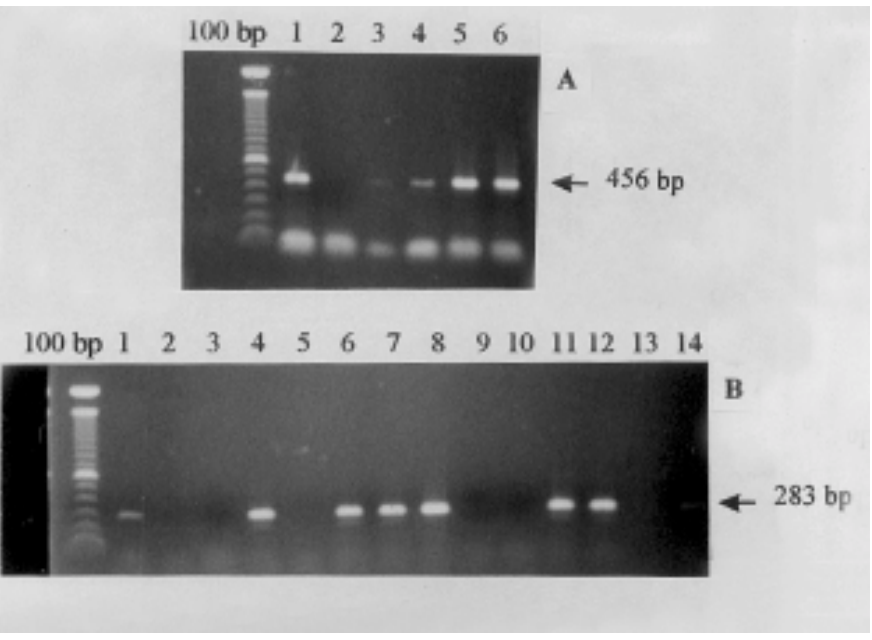

Fig. 2 - A: Identification of suggestive $U$. urealyticum isolates by PCR with primers Uu3 and Uu4. Lanes 1: Positive control; 2: negative control; 3-6: samples which changed the color of U10 broth culture tubes. B: identification of $U$. urealyticum serotypes belonging to biotype 2 with primers Uu1 and Uu2. Lanes 1: positive control; 2: negative control; 4, 6, 7, 8, 11, 12 and 14: positive samples; 3, 5, 9, 10 and 13: negative samples. Weight marker: 100 bp DNA Ladder.

Ouchterlony's technique and PCR (Fig. 1), as well as for U. urealyticum (Fig. 2). In the HIV group, $50 \%$ of the $U$. urealyticum strains were distributed in each cluster ( $p=1.25)$, and in the STD group, 53.3\% were classified in the biotype 1 and $46.7 \%$ in the biotype $2(\mathrm{p}=1.00)$. Attempts to isolate other mycoplasma species, including $M$. genitalium, $M$. fermentans or M. penetrans by culture failed, from both urine and urethral swab samples of the HIV- infected and STD groups of patients.

\section{Quantification of the isolates}

In the HIV group, $62.5 \%$ of the M. hominis isolates were in relevant concentrations $\left(\geq 10^{3} \mathrm{CCU} / \mathrm{mL}\right)$, and for $U$. urealyticum, this rate was $85 \%\left(\geq 10^{4} \mathrm{CCU} / \mathrm{mL}\right)$. In the STD group, $100 \%$ and $93.3 \%$ of the $M$. hominis and $U$. urealyticum isolates were in relevant concentrations.

\section{DISCUSSION AND CONCLUSIONS}

$M$. hominis and $U$. urealyticum are commonly found in the genitourinary tract as the causative agents of several sexually transmitted diseases. In men, U. urealyticum is one of the major causes of nongonococcal urethritis, which may also have participation of $M$. hominis in a lesser extension ${ }^{17}$. In our work, we found a relevant prevalence of these urogenital mycoplasmas in two groups of patients, HIV-infected ones and persons presenting with urethritis. The higher rate of urogenital mycoplasmas in the HIV group suggests at least two hypotheses. First, the immune deficiency associated with HIV infection could be a predisposing factor for mycoplasma urogenital infections. Because there was no correlation between the detection of mycoplasmas and the CD4+ $\mathrm{T}$ cell number or the $\mathrm{CD}_{4} / \mathrm{CD}_{8}$ ratio in the HIV group (data not shown), the immune deficiency predisposing to the mycoplasma colonization must be an early event during the HIV infection. The second hypothesis is that the increased frequency of mycoplasmas could be related to homosexual/bisexual practices, hence its higher rate in some HIV-infected patients, as suggested for $M$. penetrans previously by others ${ }^{19}$. This higher frequency of urogenital mycoplasma infections in HIV-infected patients may have a possible implication regarding the transmissibility of HIV. Indeed, it has been shown that various STD, including the non-ulcerative ones, can facilitate the sexual transmission of HIV ${ }^{13}$.

The fact that we could demonstrate a relevant rate of $U$. urealyticum and especially a higher $M$. hominis infection rate in the HIV-1 infected patients group, who presented no apparent symptoms of urethritis, is very interesting and must be remarked by at least two aspects. In patients with hypogammaglobulinemia or cell-mediated immune response suppressed, especially $M$. hominis may have extragenital manifestations, causing a great damage to the host, such as vascular, wound, joint, CNS and respiratory tract infections ${ }^{10}$. In many of these patients, the ultimate source of $M$. hominis infection was the genitourinary tract, but the hypothesis that this microorganism may have hematogenous dissemination or invasive disease by other routes must be taken in account. An increased frequency of $U$. urealyticum and M. genitalium infection rates in HIV-infected patients has also been recently reported by others, with a similar rate of $U$. urealyticum infection (12.3\%) as the one obtained in our work ${ }^{9}$. Like $M$. hominis, this species has also been shown to produce extragenital infections, specially in patients with antibody deficiency, causing pneumonitis, sinusitis, cystitis, arthritis, osteomyelitis, cellulitis and chronic sinopulmonary disease ${ }^{5}$. Thus, by the infection rates observed in our study, these microorganisms may be playing a more important role in HIV-infected individuals in our population than the most part of clinicians and investigators currently suspect. Therefore, its participation in some severe syndromes in this group of patients, frequently not diagnosed, may be underestimated. Otherwise, even in infections restricted to the genitourinary tract, we do not know if relevant 
concentrations of a lesser pathogenic serotype of $U$. urealyticum is more significant than a lower concentration of a more pathogenic serotype. The extension of these pathogenicity differences among M. hominis strains is still not known. Therefore, only studies including determination of $U$. urealyticum serotypes or $M$. hominis strains differences may help us to correctly evaluate their role in human diseases, specially in immunosuppressed patients infections.

Furthermore, beyond the fact that the defective immune response of these individuals may favour their establishment, these microorganisms, mainly $M$. hominis, may be playing more relevant pathogenic roles even in progression of AIDS disease. This can be hypothesised once they have, at least in vitro, properties that can modulate the host immune system ${ }^{14}$, such as arginine depletion, cytotoxicity toward lymphoid cells, activation of monocytes and polymorphonuclear cells, induction of cytoquines production, etc. However, the extend that $M$. hominis interaction may have systemically in modulating the immune system is still not known. As we can see, in spite of the evolution that science as a whole could accomplish in the last years, there are several aspects in human mycoplasma infections that remain unclear. We believe that the prevalence and the role of these microorganisms in immunosuppressed patients must be more extensively investigated.

\section{RESUMO}

\section{Prevalência relevante de Mycoplasma hominis e sorogrupos de Ureaplasma urealyticum em homens infectados pelo HIV-1 sem sintomas de uretrite}

M. hominis e $U$. urealyticum são as espécies de micoplasmas mais conhecidas como patogênicas para o trato geniturinário humano, causando principalmente uretrite, vaginose bacteriana e complicações da gravidez. Em pacientes infectados pelo HIV, a prevalência e o papel destas espécies ainda não está bem estabelecido. O objetivo do presente estudo foi comparar a prevalência das espécies acima referidas na uretra de pacientes masculinos portadores do vírus HIV (Grupo HIV) com a prevalência das mesmas entre homens não portadores do HIV mas com sintomas de uretrite (grupo DST). No grupo HIV, M. hominis foi isolado de $7,5 \%$ pacientes $(8 / 106)$ e $U$. urealyticum de $18,9 \%$ pacientes $(20 /$ 106) em concentrações significativas de $62,5 \%$ e $85 \%$ respectivamente. No grupo DST estas taxas foram 0,9\% (1/110) para M. hominis e 13,6\% (15/110) para U. urealyticum, sendo $100 \%$ e $93,3 \%$ em concentrações significantes, respectivamente. Pôde-se demonstrar que no grupo HIV as taxas de infecção por estes micoplasmas foram tão elevadas quanto as observadas no grupo DST. Tais achados podem indicar a ocorrência de infecção oportunista, o que, em pacientes imunocomprometidos representa risco de desenvolvimento de infecções sistêmicas.

\section{ACKNOWLEDGEMENTS}

This work was supported by FAPESP grant and CAPES fellowship.

\section{REFERENCES}

1. ALFA, M.J.; EMBREE, J.E.; DEGAGNE, P. et al. - Transmission of Ureaplasma urealyticum from mothers to full and preterm infants. Pediat. infect. Dis. J., 14: 341-345, 1995.
2. BARBEYRAC, B.; BÉBÉAR, C. \& TAYLOR-ROBINSON, D. - PCR: preparation of DNA from clinical specimens. In: TULLY, J.G. \& RAZIN, S. Molecular and diagnostic procedures in mycoplasmology. Diagnostic procedures-1996. San Diego, Academic Press, 1996. v. 2. p. 61-64.

3. BLANCHARD, A. - Ureaplasma urealyticum urease genes; use of UGA tryptophan codon. Molec. Microbiol., 4: 669-676, 1990.

4. CUNHA, R.A.F.; KOIFFMAN, C.P.; SOUZA, D.H. \& TAKEI, K. - Clastogenic effects of different Ureaplasma urealyticum serovars on human chromossomes. Braz. J. med. biol. Res., 30: 749-757, 1997.

5. GELFAND, E.W. - Unique susceptibility of patients with antibody deficiency to mycoplasma infection. Clin. infect. Dis., 17(suppl. 1): S250-S253, 1993.

6. HEGGIE, A.D.; JACOBS, M.R.; BUTLER, V.T.; BALEY, J.E. \& BOXERBAUM, B. Frequency and signification of isolation of Ureaplasma urealyticum and Mycoplasma hominis from cerebrospinal fluid and tracheal aspirate specimens from low birth weight infants. J. Pediat., 24: 956-961, 1994.

7. KOCH, A.; BILINA, A.; TEODOROWICZ, L. \& STARY, A. - Mycoplasma hominis and Ureaplasma urealyticum in patients with sexually transmitted diseases. Wien. Klin. Wschr., 109: 584-589, 1997.

8. van KUPPEVELD, F.J.M.; van der LOGT, J.T.M.; ANGULO. A.F.; van ZOEST, M.J. \& QUINT, W.G.V. - Genus- and species-specific identification of mycoplasmas by $16 \mathrm{~S}$ rRNA amplification. Appl. environ. Microbiol., 58: 2606-2615, 1992.

9. MARTINELLI, F.; GARRAFA, E.; TURANO, A. \& CARUSO, A. - Increased frequency of detection of Ureaplasma urealyticum and Mycoplasma genitalium in AIDS patients without urethral symptoms. J. clin. Microbiol., 37: 2042-2044, 1999.

10. MEYER, R.D. \& CLOUGH, W. - Extragenital Mycoplasma hominis infections in adults: emphasis on immunosuppression. Clin. infect. Dis., 17(suppl. 1): S243-S249, 1993.

11. MÖLLER, B.R.; HERRMAN, B.; IBSEM, H.H. et al. - Occurrence of Ureaplasma urealyticum and Mycoplama hominis in non-gonococcal urethritis before and after treatment in a double-blind trial of ofloxacin versus erithromycin. Scand. J. infect. Dis., 68: S31-S34, 1990.

12. OUCHTERLONY, O. - Antigen-antibody reaction in gels. Acta path. microbiol. immunol. scand. Sect. B: Microbiol., 26: 507-515, 1949.

13. PLUMMER, F.A. - Heterosexual transmission of human immunodeficiency virus type 1 (HIV): interactions of conventional sexually transmitted diseases, hormonal contraception and HIV-1. AIDS Res. hum. Retrovir., 14(suppl. 1): S5-S10, 1998

14. RAZIN, S.; YOGEV, D. \& NAOT, Y. - Molecular biology and pathogenicity of mycoplasmas. Microbiol. Molec. Rev., 62: 1094-1156, 1998.

15. SHEPARD, M.C. \& LUNCEFORD, C.D. - Differential agar medium (A7) for identification of Ureaplasma urealyticum (Human T Mycoplasma) in primary cultures of clinical material. J. clin. Microbiol., 3: 613-625, 1976.

16. TAYLOR-ROBINSON, D. - Diagnosis of sexually transmitted diseases. In: TULLY, J.G. \& RAZIN, S. Molecular and diagnostic procedures in mycoplasmology. San Diego, Academic Press. 1996a. v. 2, p. 225-236.

17. TAYLOR-ROBINSON, D. - Infections due to Mycoplasma and Ureaplasma: an update. Clin. infect. Dis., 23: 671-684, 1996b.

18. TAYLOR-ROBINSON, D. - Genital mycoplasma infections. Wien. Klin. Wschr., 109: 578-583, 1997.

19. TAYLOR-ROBINSON, D. \& AINSWORTH, J. - Antibodies to Mycoplasma penetrans in HIV-infected patients. Lancet, 341: 557-558, 1993.

Received: 27 December 1999

Accepted: 13 April 2000 